\title{
Predictors of Australian consumers' intentions to consume conventional and novel sources of long-chain omega-3 fatty acids
}

\author{
DN Cox*, G Evans and HJ Lease \\ CSIRO Food Futures National Research Flagship and CSIRO Human Nutrition, PO Box 10041, Adelaide BC, \\ South Australia 5000, Australia
}

Submitted 10 August 2006: Accepted 31 January 2007: First published online 3 July 2007

\begin{abstract}
Objectives: To elicit predictors of variation in likelihood to purchase foods rich in long-chain omega-3 fatty acids.

Design, setting and subjects: Responses from a community sample $(n=220)$ were elicited using a computer-administered questionnaire based on an adaptation of Protection Motivation Theory including measures of perceived risk and vulnerability to coronary heart disease (CHD). Other measures included health status, body mass index (BMI), perceived risk/benefits of novel technologies and sociodemographics. Descriptions of model products were presented, including farmed fish fed fishmeal (FFFF); farmed fish fed genetically modified (GM) oilseed (FFFGM); bread, milk and supplements containing fish oil (SFO) or GM oilseed. It was hypothesised that perceived vulnerability to CHD would enhance acceptance of GM products (H1). Furthermore, information describing the benefits of LCO3FA, limitations to fish supply and potential alternatives was given to a treatment group (50\%) and hypothesised to have a positive effect on the acceptance of GM products (H2).

Results: No evidence was found to support H1 or H2. FFFF was most likely to be purchased $(P<0.01)$, followed by SFO and FFFGM. Multivariate regression analysis identified significant $(P<0.05)$ predictors (standardised $\beta$ ) for likelihood to purchase FFFF: self-efficacy 0.56; behaviour (product) efficacy 0.19; belief that fishmeal is unnatural $-0.14\left(R^{2}=0.44\right)$ and for FFFGM: self-efficacy 0.65 ; perceived severity of CHD 0.15; BMI -0.13 ; significant other has/had arthritis 0.11 ; belief that GM oilseed is unnatural $0.11\left(R^{2}=0.49\right)$.

Conclusions: Self-efficacy (confidence to consume) was the most important predictor of likelihood to purchase all products.
\end{abstract}

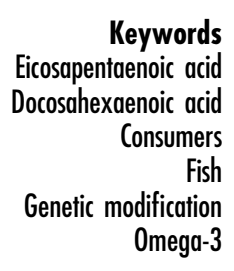

Long-chain omega-3 fatty acids (LCO3FA), eicosapentaenoic acid (EPA) and docosahexaenoic acid (DHA) have been shown to have an increasingly large range of specific health benefits in the prevention and treatment of chronic diseases, with the strongest evidence for associated reduced risk of coronary heart disease $(\mathrm{CHD})^{1-3}$. Recommend intakes are similar across the world - e.g. in Australia, $610 \mathrm{mg}$ LCO3FA for men and $430 \mathrm{mg}$ for women daily ${ }^{4}$ and, in the USA, the National Academy of Sciences ${ }^{5}$ (unofficially) recommends $500 \mathrm{mg} \mathrm{day}^{-1}$; the American Heart Association recommends CHD sufferers to consume $1000 \mathrm{mg} \mathrm{day}^{-1}$ and those seeking to reduce triglycerides $2000-4000 \mathrm{mg} \mathrm{day}^{-1}$. An international consensus workshop ${ }^{6}$ suggested $650 \mathrm{mg} \mathrm{day}^{-1}$.

By any recommendation, many Western populations' intakes fall short. For example, recent estimates suggest that adult Australians are consuming, on average, less than $189 \mathrm{mg}$ LCO3FA daily ${ }^{7}$. In the USA, recent estimates of intakes of EPA and DHA were between 56 and $100 \mathrm{mg} \mathrm{day}^{-1}$, suggesting a large shortfall in intakes ${ }^{5,8}$.

Currently, oily fish (including salmon, tuna, sardines, pilchards and mackerel) are the only rich source of LCO3FA, EPA and DHA available. To meet the above recommended daily intakes, a minimum consumption of two servings a week is required ${ }^{4,8}$.

Increasing numbers of enriched common foods including milk and bread products ${ }^{9}$ enriched with microencapsulated fish oil, and eggs - have become available in addition to fish oil capsules, giving consumers more dietary choice.

However, consumer awareness regarding the benefits of LCO3FA increases demand for fish, fish oil supplements 
and fish-oil-enriched foods, placing an increasing strain on wild fisheries, which are at maximum levels of exploitation with some declining. Some of the increasing global demand for fish is being met by aquaculture; but aquaculture is also dependent on wild-caught fish for fishmeal $^{10}$, suggesting a need to explore alternative methods of producing LCO3FA.

While some land plants do produce omega-3 oils, these are short-chain and do not have the same degree of associated health benefits. Thus there is a need to create an alternative, sustainable source of LCO3FA ${ }^{11}$.

LCO3FA are produced initially by marine micro-algae ${ }^{12}$; fish feed, via their food chain, on these marine microalgae, which results in the accumulation of LCO3FA in their fatty tissue. Thus a potential solution is to transfer the genes responsible for the production of LCO3FA in marine micro-algae to land-based plants $^{13}$, thereby creating a genetically modified (GM) oilseed equivalent in LCO3FA content to fish oil. GM oilseeds could provide a sustainable, cheaper and renewable source of LCO3FA whilst reducing demand on wild fish stocks.

The oilseeds could supplement or replace fish oil in enriched foods such as breads and milks and replace wild fish as feed for farmed fish, thus resulting in improved sustainability and cost of aquaculture.

However, it is known that transgenic technologies (genetic modification, GM) often generate high perceived risk and aversion ${ }^{14}$. In the past, many GM foods were designed to provide producer benefits (e.g. lower production costs) and, whilst these may have had some secondary consumer benefit, such benefits were generally not appreciated relative to the perceived risks. The foods of interest in the current study represent so-called second-generation GM food products that have direct consumer benefits, i.e. a health benefit, and an additional secondary benefit of sustainable production ${ }^{15,16}$. Only a few studies have investigated consumer reactions to second-generation GM products ${ }^{15-19}$ and results have been generally positive.

Given the novelty and complexity of the health, nutrient and supply issues, together with an absence of knowledge of community awareness, we adopted a 'knowledge deficit' approach and provided extensive information (similar to the above introduction) generating a hypothesis that those receiving the extra information (50\%) would express more positive responses. Nevertheless, we were aware of the possible redundancy of the knowledge deficit approach from European data ${ }^{20,21}$ and one suggestive study from Australia ${ }^{22}$ on attitudes towards GM that simply addressing the 'information deficit' does little to assuage fears and may indeed accentuate existing (negative) attitudes (an attitude activation effect). However, it is not known whether the redundancy of the information deficit model applies to specific secondgeneration (consumer benefit) GM products such as those investigated in the current study.
The current paper reports a predictive survey that sought to assess consumer attitudes as drivers of intentions to consume a range of products that are currently or could be rich sources of LCO3FA. Included within the survey instrument was also a conjoint design (assessing product-attribute drivers of intentions to consume); however this will be reported elsewhere.

A previous study recently undertaken in Australia ${ }^{23}$ used the Theory of Planned Behaviour to identify predictors of intentions to consume novel cereal and milk products enriched with omega- 3 fatty acids and found that attitude was the only significant predictor. Antecedents of those attitudes that distinguished between intenders and non-intenders included beliefs about product efficacy and ease of consumption (self-efficacy). Importantly, in terms of improving intentions to consume, the authors concluded that promotion of product effectiveness was required, hence providing further support for an information intervention (treatment). Furthermore, they stated that it is important to study specific foods and that their results could not be applied to other LCO3FArich products such as fish oil supplements or use of GM. The current study included information on product efficacy and sought to identify predictors of these foods by using an extended model of Protection Motivation Theory (PMT) (including product efficacy and self-efficacy) ${ }^{24}$.

PMT has successfully been applied to perceptions of health-enhancing foods and supplements ${ }^{25,26}$. The theory lends itself to this type of investigation as it attempts to specify the precise characteristics of a health message or behaviour that influence compliance and the processes at work $^{24}$. These message characteristics include four categories of information surrounding perceptions: the severity of the health threat, one's vulnerability to this threat, how efficacious the proposed behaviour is at averting the threat and how efficacious one is at carrying out this advocated behaviour (in this case, consuming LCO3FA-rich foods or supplements). Two cognitive processes are activated that subsume the severity, vulnerability, self-efficacy and response-efficacy elements when one encounters a health threat from the environment: the threat appraisal process and the coping appraisal process ${ }^{24}$.

Based upon previous research on functional foods ${ }^{25,26}$ and the GM literature ${ }^{19}$, in order to improve on the variance explained, independent variables additional to PMT were included (see below).

\section{Hypotheses}

The study was largely exploratory; however, tentative hypotheses were tested:

- H1 - Perceived vulnerability to CHD will motivate likelihood to purchase (intentions) and have a differential effect on the acceptability of consuming novel products rich in LCO3FA. 
- H2 - Participants (treatment group) given additional information on the limitations surrounding the current source of LCO3FA (fishing and fish farming) are likely to be more accepting of novel products.

\section{Methodology}

\section{Stimuli}

Food product descriptions were described using a structure used for conjoint studies facilitating realistic product information $^{27,28}$. The details of this technique and analyses of these data will be reported elsewhere. In summary, text descriptions of the food products were created from eight product attributes and (a maximum of) five levels, which resulted in creating 25 product profiles (plus two holdouts) for an orthogonal design (SPSS version 14 Conjoint). Typically, these were text descriptions of model products that closely represent potential options for consumption. They included fish, currently available enriched foods 9 and novel products including those that involve GM for direct human consumption or consumption by fish (fish food) ${ }^{12,13}$

In summary, the three key points that the product descriptions made were simply: LCO3FA are beneficial; that fish supply is unsustainable at present (wild-caught or farmed) to meet human health needs; and that viable alternatives are needed.

\section{Participants}

A sample was sought that would facilitate variation in risk factors (e.g. high cholesterol, weight status, etc. ${ }^{29}$ which are in turn strongly associated with age (older) and gender (male), resulting in a sample above 30 years of age (and below 75 years) and with a gender ratio of 1:1, stratified by age according to the population ${ }^{30}$.

All were recruited on the basis that they consumed bread and milk regularly (at least 1-3 times a week) and had no perceived allergies to fish (excluding shellfish allergy).

At recruitment, no mention was made of GM or biotechnology in an effort to reduce bias ${ }^{15}$.

Participants were recruited by a market research company, following recruitment criteria specified above, from their consumer database. Each participant was compensated AU $\$ 40$ for their time. The study was approved by the Commonwealth Scientific and Industrial Research Organisation (CSIRO) Human Nutrition Human Ethics Committee.

\section{Metbods}

Additional information was given, prior to the study, to a treatment group $(n=110,50 \%)$ on the constraints surrounding the current source of LCO3FA (fishing and fish farming); this was hypothesised to have a positive effect on acceptance and likelihood to consume novel products.
The product descriptions (available on request from the corresponding author) given to all participants also contained information in this respect (a balanced set of information describing technologies, benefits and concerns). However, we hypothesised that participants given additional information prior to questionnaire administration were likely to be more accepting of novel products.

\section{Questionnaire}

\section{Protection motivation}

Attitudes that may predict the primary dependent variable ('likelihood to purchase') were measured using an adaptation of a validated model of $\mathrm{PMT}^{23}$ with high predictive value in respect to other health-enhancing foods $^{25,26}$.

\section{Risks and benefits of novel technologies}

In addition, five questions were asked about risks and benefits of each novel technology, e.g. 'To what extent do you think foods containing long-chain omega-3 oils derived from GM plants is necessary/unnatural/beneficial/safe for you/safe for the environment? ${ }^{19}$ Each PMT and risk/benefit item and the corresponding response scale are shown in Table 1.

\section{Risk factors}

Other CHD risk factors were assessed using an adaptation of our laboratory's clinical trial screening questionnaire (unpublished) and a validated leisure activity questionnaire $^{31,32}$. Information on sociodemographics was collected and participants' heights and weights were also measured in order to determine body mass index (BMI, weight status). Selected food intakes were measured using extracts from a validated food-frequency questionnaire ${ }^{33}$. See Table 1 for a description of the predictor (independent) variables.

\section{Presentation}

The questionnaire was presented to participants on a custom-designed Intranet (CSIRO's internal web server)based platform (Microsoft Explorer) using Frontpage (Microsoft Inc.) as an interface on computer monitors in individual booths at our laboratory. A copy of the questionnaire is available on request from the corresponding author.

\section{Analysis}

Independent variables including sociodemographic characteristics, CHD risk factors and psychological variables from an adaptation of PMT were used to predict variation in 'likelihood to consume' specific products as described in the text profiles. Multiple item constructs were tested for internal consistency using Cronbach's $\alpha$ 
Table 1 Independent variables and internal consistency (multi-item) when entered in the multiple regression model

\begin{tabular}{|c|c|c|}
\hline Variable name (number of items if more than one) & Responses & $\begin{array}{l}\text { Cronbach's } \alpha \\
\text { or correlation }(r)\end{array}$ \\
\hline Gender & male/female & \\
\hline Age & five categories & \\
\hline Education status & $\begin{array}{l}<\text { high school; completed high school; } \\
\text { trade/diploma; tertiary }\end{array}$ & \\
\hline Body mass index & continuous & \\
\hline Smoking & yes/no & \\
\hline Alcohol consumption & $\begin{array}{l}\text { rarely or none; low }\left(1-2 \text { units day }^{-1}\right) \\
\quad \text { high }\left(>2 \text { units day }{ }^{-1}\right)\end{array}$ & \\
\hline Fish consumption & $1-5 \S$ & \\
\hline Bread consumption & $1-5$ & \\
\hline Milk consumption & $1-5$ & \\
\hline Consumption of bread with fish oil & $1-5$ & \\
\hline Consumption of milk with fish oil ${ }^{\star}$ & $1-5 \uparrow$ & \\
\hline Dietary supplement use & yes/no & \\
\hline Behaviour (product) efficacy (2) & $1-7$ & $r=0.68$ \\
\hline Self-efficacy (fish fed fishmeal) + & $1-7$ & \\
\hline Self-efficacy (fish fed GM oilseed)† & $1-7$ & \\
\hline Self-efficacy (bread with fish oil) $\dagger$ & $1-7$ & \\
\hline Self-efficacy (bread with GM oilseed) $\dagger$ & $1-7$ & \\
\hline Self-efficacy (milk with GM oilseed) $\dagger$ & $1-7$ & \\
\hline Self-efficacy (milk with fish oil)t & $1-7$ & \\
\hline Self-efficacy (fish oil supplements)† & $1-7$ & \\
\hline Self-efficacy (GM oilseed supplements) $\dagger$ & $1-7$ & \\
\hline Perceived severity of CHD (3) & $1-7$ & $\alpha=0.67$ \\
\hline Perceived vulnerability to CHD (4)‡ & $1-7$ & $\alpha=0.75$ \\
\hline Significant other is overweight & yes/no & \\
\hline Participant has/had diabetes & yes/no & \\
\hline Significant other has/had diabetes & yes/no & \\
\hline Participant has/had angina & yes/no & \\
\hline Significant other has/had angina & yes/no & \\
\hline Participant has/had CHD & yes/no & \\
\hline Significant other has/had CHD & yes/no & \\
\hline Participant has/had diagnosed high cholesterol & yes/no & \\
\hline Significant other has/had diagnosed high cholesterol & yes/no & \\
\hline Participant has/had stroke & yes/no & \\
\hline Significant other has/had stroke & yes/no & \\
\hline Participant has/had arthritis & yes/no & \\
\hline Significant other has/had arthritis & yes/no & \\
\hline Participant has/had diagnosed high blood pressure & yes/no & \\
\hline Significant other has/had diagnosed high blood pressure & yes/no & \\
\hline Reported exercise & score (Godin \& Shepherd ${ }^{31}$ ) & \\
\hline Belief that GM oilseed is unnatural & $1-7$ & \\
\hline Belief that fishmeal is unnatural & $1-7$ & \\
\hline Perceived risk/benefit of GM oilseed (4) & $1-7$ & $\alpha=0.89$ \\
\hline Perceived risk/benefit of fishmeal (4) & $1-7$ & $\alpha=0.89$ \\
\hline
\end{tabular}

GM - genetically modified; CHD - coronary heart disease.

${ }^{*}$ Excluded as $<9 \%$ reported any consumption.

t Only one specific item entered for each product-specific regression model.

‡Log-transformed.

$\S 1=$ Never; $2=$ rarely; $3=1-3$ times per month; $4=1-3$ times per week; $5=4-7$ or more times per week. As there were very few respondents who reported never or rarely consuming these foods, the data were collapsed with 'consumed less than 3 times per month' (those responding 1 , 2 or 3 ) labelled low consumption and 'greater than 3 times per month' (those responding 4 or 5 ) labelled high consumption.

- 1 = Never; 2 = rarely; $3=1-3$ times per month; $4=1-3$ times per week; $5=1-3$ or more times per day (these data were collapsed into 'low consumption' and 'high consumption' as indicated above).

and correlations (see Table 1). The risk/benefit construct was also subjected to factor analysis as described in a previous study ${ }^{34}$. In summary and as in the previous study, the item 'unnatural' was found to be a distinct construct and therefore entered into the regression equations separately from the other four risk/benefit items (necessary/beneficial/safe for you/safe for the environment).

Costs of undertaking the protective dietary behaviours (as part of the PMT model) were operationalised as responses to questions about liking, convenience and expense ('expensive') for each of the four base products (fish, milk, bread and supplements). Factor analysis (principal components analysis using Varimax rotation with Kaiser normalisation) revealed that for all products 'expensive' was a separate component and that 'liking' and 'convenience' grouped together into product-specific components (data not shown). Thus liking and convenience' was used in further analysis as one composite independent variable and 'expensive' as a separate variable. 
The dependent variable scores for 'likelihood to consume' were combined from the 25 product profiles using the two most important perceived attributes as determined by conjoint analysis, specifically 'base product' (averaged importance 32\%) and 'technology' (averaged importance 21\%), resulting in eight 'types' of products (see Table 2 below) reflecting 53\% of the perceived importance of the product attributes. Overall the product combinations also had various content and health claims attached to them. Because of the orthogonal design these would have been distributed over all base products.

Because many products were not yet available and therefore it was not possible to measure behaviour, we were restricted to intentions - specifically 'likelihood to purchase'. A meta-analysis of correlational studies of PMT found that the average correlation between protection motivation intentions and future behaviour was $r=0.40^{35}$.

Multiple regression analysis was undertaken using the backward elimination method whereby independent variables in the model were entered and $F$-statistics calculated for each variable. The variable with the largest $P$-value exceeding the specified $\alpha$ cut-off value of 0.1 was then removed from the model. The process was continued until no remaining variables had $F$-statistic $P$-values above 0.05 .

Examination of the residual scatter plots for each variable indicated that one, namely 'perceived vulnerability', was heteroscedastic. To eliminate this problem, this variable was normalised using log transformation.

In addition, repeated-measures analysis of variance (ANOVA) and post boc tests were used to determine differences in preferences ('likelihood to purchase') towards the product concepts.

\section{Results}

Results are presented for the whole sample as the intervention treatment (extra information) had no effect on any outcome variable, i.e. hypothesis $\mathrm{H} 2$ is rejected.

\section{Participants' characteristics}

Participants were successfully recruited from metropolitan Adelaide (South Australia) by age (over 30 years, as specified above) and 52\% were female. More participants reported tertiary education status (30\%) than found in the general population, $19.5 \%^{30}$. Three-quarters (76\%) were found to be overweight or obese (although only 25\% considered themselves to be overweight or obese) and mean BMI was $28.8 \mathrm{~kg} \mathrm{~m}^{-2}$. Only $5 \%$ reported current or past heart disease but 35\% reported a significant other (partner, spouse, friend or relative) with current or past heart disease. Over 20\% reported current or past arthritis and a third (34\%) reported a significant other with current or past arthritis.
Regular milk consumption was frequent, with more than $75 \%$ reporting consumption $1-3$ times per week or 1-3 times per day. Regular bread consumption was common (95\% reporting 1-3 times weekly or 1-3 times daily). More than half (59\%) reported fish consumption 1-3 times per week or 1-3 times per day, with a further third reporting 1-3 times per month, and over half (53\%) reported dietary supplement use.

\section{Product preferences}

Repeated-measures ANOVA (generalised linear model) on the dependent variables, 'likelihood to purchase' the eight omega-3 products, were undertaken. The analysis showed a significant between-technologies (non-GM vs. GM oilseed) effect $(F=31.57$; df $=[1,219] ; P<0.001)$ and significant differences between products within the technologies for 'current' products (Greenhouse-Geisser: $F=35.40 ; \mathrm{df}=[3,555] ; P<0.001)$ and also for 'novel' products (Greenhouse-Geisser: $F=8.02 ; \quad$ df $=[3,593]$; $P<0.001$ ). Post hoc analysis (Table 2 ) indicated that there were significant differences between 'non-GM' vs. 'GM oilseed' fish, bread and supplements $(P<0.001)$, but not between 'non-GM' vs. 'GM oilseed' milk. The post hoc analysis also indicated there were differences between most products $(P<0.01)$, but not between either 'nonGM' or 'GM oilseed' bread and supplements, 'GM oilseed' milk and bread, or 'GM oilseed' milk and supplements $(P>0.05)$.

\section{Predictors}

Table 3 shows significant predictors from the multiple regression modelling for 'likelihood to purchase' each of the eight products.

Generally the percentage variance $\left(R^{2}\right)$ accounted for was high, ranging from 44 to $51 \%$, suggesting that the independent variables chosen were particularly appropriate. The evidence does not provide support for the hypothesis (H1) that vulnerability to CHD would drive likelihood to purchase novel products. Only for the likelihood to purchase fish oil supplements (an existing

Table 2 Univariate contrast effects on mean scores for 'likelihood to purchase' (1-7) LCO3FA-rich products $(n=220)$

\begin{tabular}{lcc}
\hline LCO3FA-rich product & $\begin{array}{c}\text { Mean score for } \\
\text { 'likelihood to purchase' }\end{array}$ & SEM \\
\hline Farmed fish (fed fishmeal) & $5.14^{\mathrm{a}}$ & 0.09 \\
Fish oil supplements & $4.61^{\mathrm{b}}$ & 0.12 \\
Bread with fish oil & $4.44^{\mathrm{b}}$ & 0.10 \\
Farmed fish (fed GM oilseed) & $4.41^{\mathrm{b}}$ & 0.11 \\
Bread with GM oilseed & $4.11^{\mathrm{c}}$ & 0.11 \\
GM oilseed supplements & $4.03^{\mathrm{c}}$ & 0.12 \\
Milk with fish oil & $3.88^{\mathrm{c}}$ & 0.11 \\
Milk with GM oilseed & $3.87^{\mathrm{c}}$ & 0.12 \\
\hline
\end{tabular}

LCO3FA - long-chain omega-3 fatty acids; SEM - standard error of the mean; GM - genetically modified.

$a, b, c$ Values not sharing a common subscript letter are significantly different $(P<0.01$, Bonferroni $\alpha<0.0035)$. 
Table 3 Predictors (unstandardised $\beta$ (SE) and standardised $\beta$ ) of variation in 'likelihood to purchase' products containing LCO3FA

\begin{tabular}{|c|c|c|c|c|}
\hline & Unstandardised $\beta$ (SE) & Standardised $\beta$ & $P$ & $R^{2}$ \\
\hline $\begin{array}{l}\text { Dependent variable: Farmed fish (fed } \\
\text { (Constant) } \\
\text { Self-efficacy (fish fed fishmeal) } \\
\text { Behaviour (product) efficacy } \\
\text { Belief that fishmeal is unnatural }\end{array}$ & $\begin{array}{r}6.90(4.16) \\
3.39(0.32) \\
1.14(0.31) \\
-0.87(0.31)\end{array}$ & $\begin{array}{r}0.56 \\
0.19 \\
-0.14\end{array}$ & $\begin{array}{l}0.0984 \\
0.0000 \\
0.0002 \\
0.0061\end{array}$ & 0.44 \\
\hline $\begin{array}{l}\text { Dependent variable: Farmed fish (fed } \\
\text { (Constant) } \\
\text { Self-efficacy (fish fed GM oilseed) } \\
\text { Perceived severity of CHD } \\
\text { BMl } \\
\text { Belief that GM oilseed is unnatural } \\
\text { Significant other has/had arthritis }\end{array}$ & $\begin{array}{r} \\
5.24(2.17) \\
2.21(0.18) \\
0.27(0.09) \\
-0.14(0.05) \\
0.44(0.20) \\
1.51(0.68)\end{array}$ & $\begin{array}{r}0.65 \\
0.15 \\
-0.13 \\
0.11 \\
0.11\end{array}$ & $\begin{array}{l}0.0164 \\
0.0000 \\
0.0028 \\
0.0116 \\
0.0314 \\
0.0273\end{array}$ & 0.49 \\
\hline $\begin{array}{l}\text { Dependent variable: Bread with fish } \\
\text { (Constant) } \\
\text { Self-efficacy (bread with fish oil) } \\
\text { Significant other is overweight } \\
\text { Has/had arthritis }\end{array}$ & $\begin{array}{r}5.49(1.44) \\
2.14(0.16) \\
-2.22(0.69) \\
2.07(0.75)\end{array}$ & $\begin{array}{r}0.65 \\
-0.16 \\
0.13\end{array}$ & $\begin{array}{l}0.0002 \\
0.0000 \\
0.0015 \\
0.0064\end{array}$ & 0.51 \\
\hline $\begin{array}{l}\text { Dependent variable: Bread with GM c } \\
\text { (Constant) } \\
\text { Self-efficacy (bread with GM oilseed) } \\
\text { Perceived severity of CHD } \\
\text { Significant other is overweight } \\
\text { Has/had arthritis }\end{array}$ & $\begin{array}{r}1.78(0.74) \\
1.14(0.08) \\
0.12(0.04) \\
-0.90(0.36) \\
0.89(0.40)\end{array}$ & $\begin{array}{r}0.67 \\
0.14 \\
-0.13 \\
0.11\end{array}$ & $\begin{array}{l}0.0175 \\
0.0000 \\
0.0064 \\
0.0124 \\
0.0258\end{array}$ & 0.50 \\
\hline $\begin{array}{l}\text { Dependent variable: Milk with fish oil } \\
\text { (Constant) } \\
\text { Self-efficacy (milk with fish oil) } \\
\text { Perceived risk of GM oilseed } \\
\text { Has/had arthritis } \\
\text { Perceived severity of CHD }\end{array}$ & $\begin{array}{r}-1.31(1.52) \\
1.64(0.14) \\
0.35(0.10) \\
1.76(0.64) \\
0.17(0.07)\end{array}$ & $\begin{array}{l}0.62 \\
0.18 \\
0.14 \\
0.12\end{array}$ & $\begin{array}{l}0.3895 \\
0.0000 \\
0.0005 \\
0.0066 \\
0.0206\end{array}$ & 0.45 \\
\hline $\begin{array}{l}\text { Dependent variable: Milk with GM oil } \\
\text { (Constant) } \\
\text { Self-efficacy (milk with GM oilseed) } \\
\text { Has/had arthritis } \\
\text { Perceived severity of CHD } \\
\text { Total exercise } \\
\text { Significant other is overweight } \\
\text { Regular milk consumption }\end{array}$ & $\begin{array}{r}-0.99(1.18) \\
1.08(0.10) \\
1.43(0.45) \\
0.14(0.05) \\
0.04(0.02) \\
-0.94(0.42) \\
0.32(0.15)\end{array}$ & $\begin{array}{r}0.59 \\
0.17 \\
0.14 \\
0.12 \\
-0.12 \\
0.11\end{array}$ & $\begin{array}{l}0.4037 \\
0.0000 \\
0.0018 \\
0.0057 \\
0.0183 \\
0.0255 \\
0.0334\end{array}$ & 0.44 \\
\hline $\begin{array}{l}\text { Dependent variable: Fish oil supplem } \\
\text { (Constant) } \\
\text { Self-efficacy (fish oil supplements) } \\
\text { Perceived vulnerability to CHD } \\
\text { Significant other has/had angina }\end{array}$ & $\begin{array}{r}3.82(1.12) \\
1.64(0.13) \\
0.14(0.05) \\
-1.65(0.81)\end{array}$ & $\begin{array}{r}0.65 \\
0.13 \\
-0.10\end{array}$ & $\begin{array}{l}0.0008 \\
0.0000 \\
0.0116 \\
0.0428\end{array}$ & 0.48 \\
\hline $\begin{array}{l}\text { Dependent variable: GM oilseed supp } \\
\text { (Constant) } \\
\text { Self-efficacy (GM oilseed supplements) } \\
\text { Has/had arthritis } \\
\text { Belief that GM oilseed is unnatural }\end{array}$ & $\begin{array}{l}2.56(0.52) \\
1.15(0.09) \\
1.25(0.45) \\
0.26(0.11)\end{array}$ & $\begin{array}{l}0.62 \\
0.14 \\
0.12\end{array}$ & $\begin{array}{l}0.0000 \\
0.0000 \\
0.0065 \\
0.0167\end{array}$ & 0.47 \\
\hline
\end{tabular}

SE - standard error; LCO3FA - long-chain omega-3 fatty acids; GM - genetically modified; CHD - coronary heart disease; BMI - body mass index.

product) was 'vulnerability to CHD' a minor but significant predictor.

On the contrary, the most important predictor for every product was product-specific self-efficacy, operationalised as 'confidence to consume'.

There was some evidence that the 'perceived severity of CHD' is influential; however, this was only a minor significant predictor for four products. Of similar importance were 'has/had arthritis' (four products) and 'significant other has/had arthritis' (one other product) and, importantly, these were predictors of likelihood to purchase products containing GM oilseeds. The "unna- tural' construct was a significant positive predictor for three GM oilseed products and 'risk of GM oilseed' a predictor for one other non-GM product (milk with fish oil). Disagreement with the unnaturalness of fishmeal fed to fish was a positive predictor of likelihood to purchase fish fed fishmeal.

Only for milk with added GM oilseed was the consumption of the base product (regular milk) a significant predictor.

'Significant other is overweight' was a negative predictor of likelihood to purchase three products (both bread products and one GM milk product). Additionally the participant's own BMI was a negative predictor of fish fed GM oil. 


\section{Discussion}

Significant differences (Table 2) for product likelihood to purchase created three groups of products. The most likely products to be purchased were farmed fish fed fishmeal. The most likely GM product to be purchased was fish fed GM oilseed, which was not rated significantly different to two non-GM products (fish oil supplements and bread with fish oil). Both GM and fish-oil-enriched milk products were the least likely to be purchased partially reflecting the measure of recent past behaviour, with only $<3 \%$ of the sample reporting consuming milk with added fish oil daily and 93\% reporting no or rare consumption. Similarly, daily consumption of bread with added fish oil was rare $(<9 \%)$ with approximately $64 \%$ reporting no or rare consumption. Despite the continuing presence of LCO3FA (fish oil) enriched milks and bread on the market, reported frequency of consumption amongst our sample suggests that currently bread and milk with added LCO3FA would have minimal impact on recommended intakes. In contrast, a recent Australian clinical trial ${ }^{36}$, which supplied a range of enriched foods to participants resulting in increased LCO3FA intakes, found that enriched milk was the largest contributor to increased intakes and enriched bread was the third largest contributor; however, the latter was disliked for sensory reasons despite the use of microencapsulated fish oil. Notably, already overweight participants also gained weight during the initial ad libitum consumption of study foods in that study. According to manufacturers' data, the fish oil LCO3FA content of current milk products would, we estimate, require approximate consumption of a litre per day or, for current bread products, require intakes of 10 slices of bread per day (the latter has low EPA and DHA content), or combinations, to reach recommended intakes. These data suggest that fish fed GM oilseed may be the best accepted novel technology option.

Our model predicted a higher percentage of the variance than many past PMT studies ${ }^{37}$ and other behaviour intention models (e.g. the Theory of Planned Behaviour $^{38}$ ), suggesting that many relevant variables were chosen. Contrary to expectations about fear appraisal, vulnerability was only a minor predictor for one product, whilst perceived severity of CHD was a minor predictor for only some products. The dominant predictor was (product-specific) self-efficacy; in other words, variation in participants' beliefs that they had the necessary selfcontrol, ability and willpower ${ }^{39}$ to consume the protective foods was the main driver of variation in likelihood to purchase. Limited by one item, the measure for self-efficacy necessitates further studies (in preparation) seeking to explore self-efficacy in more depth and, when known, interventions are required that improve self-efficacy.

Arthritis (significant other or participant) as a positive predictor is consistent with risky or 'unnatural' technology as acceptable for medical application ${ }^{40}$. Hence, those suffering chronic pain would be more amenable to technologies that are perceived as risky to many (other) sections of the community, i.e. the perceived benefits of ameliorating the disease may override the perceived risks of the novel technology. The importance of this construct is likely to be supported by current promotion of fish oil products for this condition. The predictive ability of 'unnatural' is consistent with the acceptance of other novel technologies ${ }^{34}$ and has been shown to be generally important as perceived quality of food ${ }^{40,41}$.

Providing additional information had no effect on likelihood to purchase novel products (H2), adding further evidence in support of the redundancy of the 'information deficit' model ${ }^{14,20}$ in respect to GM. Importantly, the lack of positive effect in the current study was found when focused upon second-generation GM products with consumer and environmental benefits. However, likelihood to purchase one GM product, fish fed GM oilseed, was moderately positive and not significantly different to some existing (non-GM) products.

Caution should be exercised with respect to the likelihood to purchase data in the context of this crosssectional study. Questions remain as to what is a meaningful (as opposed to statistical) difference, particularly as product categories scores were averaged responses by base product and technology. Nevertheless, these data reflect the two most popular means of consuming LCO3FA currently available, providing some credibility for this measure. Of the novel technologies, farmed fish fed GM oilseed was the most preferred, perhaps reflecting the popularity of fish as a base product and the indirect consumption of GM foods. The unpopularity of current enriched bread and, especially, milk products was surprising, and suggests that these are not likely to be popular vehicles for increasing LCO3FA either by adding fish oil or GM oilseed to bread products for the overweight or using milk products as vehicles generally. BMI and significant other's BMI as negative predictors of likelihood to purchase enriched breads may be associated with perceptions of bread and weight control.

\section{Study limitations}

Whilst not a random stratified sample, our sample was representative of the Australian population by age (over 30 years) and gender; however, participants reported higher educational status than national estimates probably partially related to the age of our sample. Importantly, sociodemographic variables had no effect on likelihood to purchase. Greater prevalence of overweight/obese status than national estimates is also probably related to the age of our sample, a sample that is highly likely to be vulnerable to $\mathrm{CHD}^{42}$ and other conditions that may be ameliorated by increased intakes of LCO3FA.

The analysis was focused upon eight types of product concepts as dependent variables (likelihood to purchase) 
reduced from the original 25 concepts that also manipulated various levels of information source and content or health claim pertaining to LCO3FA and CHD. This additional information needs to be considered when interpreting the results, i.e. overall responses to all products were likely to be influenced by perceived credibility of information source (importance 17\%) and the type of information (content or health claim, importance 22.1\%) pertaining to all the product concepts ${ }^{43}$. The current analyses revealing differences between the eight product concepts has strength of reliability because participants gave ratings to several products which were then averaged (by base product and technology) and statistically significant differences were found (Table 2).

This study was focused upon Australian consumers and there was no emphasis given to issues of contamination of farmed fish or fishmeal in the product information provided, as such problems are thought to be minimal in Australia. Elsewhere (e.g. Northern Europe and North America), contamination issues ${ }^{44,45}$ and subsequent dietary guidelines ${ }^{46}$ may influence consumer choices in this respect and further studies are planned.

\section{Conclusions and further research}

These data suggest that fish fed GM oilseed may be the best accepted novel technology option, although preferences were clearly for (current) fish fed fishmeal and fish oil supplements. However, less than half the sample currently reported sufficient fish consumption to meet recommendations by our estimated measures. Neither vulnerability to CHD nor additional information influenced likelihood to purchase either current or novel products. This suggests that appealing to vulnerability to CHD is unlikely to be an effective public health message. Focusing upon arthritis sufferers may be more useful. However, the expanded PMT model was highly predictive of likelihood to purchase. By far the most important predictor was self-efficacy (confidence to consume), necessitating further study to understand what underlies and facilitates efficacy to make dietary choices to meet LCO3FA recommended intakes. Presenting consumers with real or purported products would clearly be a useful next step.

\section{Implications}

The expanded PMT, risk/benefit perceptions of technology, objective disease risk variables proved useful in identifying what motivates consumers' likelihood to consume foods potentially protective of health. The study suggests that (some) consumers would find GM oilseed, as a source of LCO3FA, acceptable (particularly when used as fish food). Given that GM oilseed is potentially sustainable and cheaper (than fish oil), the study suggests there is potential to improve one aspect of public health nutrition, namely increasing intakes of LCO3FA, using novel technology.

Scientific solutions (nutrient function and delivery technologies) are crucial but insufficient for having an impact on public health nutrition. Understanding consumers' motivations and acceptance of foods is also required. This study demonstrated an approach to understanding what drives uptake of protective nutrients and identified which food vehicles may be most acceptable.

\section{Acknowledgements}

Sources of funding: Funding for the study came from CSIRO Food Futures National Research Flagship.

Conflict of interest declaration: None declared.

Authorship responsibilities: D.N.C. conceived the study hypothesis, supervised data analyses and wrote the manuscript. H.J.L. took a lead role in the data collection. G.E. took a lead role in the data analysis. All co-authors made substantial contributions to data analysis and interpretation and the writing of the manuscript.

Acknowledgements: We thank Juliet Summers (PhD candidate, University of Adelaide and CSIRO Human Nutrition) for access to focus group transcripts (unpublished).

\section{References}

1 Kinsella JB, Lokesh B, Stone RA. Dietary n-3 polyunsaturated fatty acids and the amelioration of cardiovascular disease: possible mechanisms. American Journal of Clinical Nutrition 1990; 52: 1-28.

2 Abeywardena M, Nichols P, Singh S. The World of Food Ingredients 2005; (April/May): 50-4.

3 US Food and Drug Administration. FDA Announces Qualified Health Claims for Omega-3 Fatty Acids [online], 2004. Available at http://www.fda.gov/bbs/topics/news/ 2004/NEW01115.html. Accessed January 2006.

4 Baghurst K. Nutrient Reference Values for Australia and New Zealand Including Recommended Dietary Intakes [online], 2006. Available at http://www7.health.gov.au/ nhmrc/publications/synopses/n35syn.htm. Accessed June 2005.

5 National Academy of Sciences. Dietary Reference Values for Energy, Carbohydrate, Fiber, Fat, Fatty Acids, Cholesterol, Protein and Amino Acids. Washington, DC: National Academies Press, 2005.

6 Simopoulos AP, Cleland LG, eds. Omega-6/Omega-3 Essential Fatty Acid Ratio: The Scientific Evidence. World Review of Nutrition and Dietetics, Vol. 92. Basel: S Karger AG, 2003; 1-174.

7 Meyer BJ, Mann NJ, Lewis JL, Milligan GC, Sinclair AJ, Howe PRC. Dietary intakes and food sources of omega- 6 and omega-3 polyunsaturated oils. Lipids 2003; 38: 391-8.

8 Kris-Etherton PM, Shaffer Taylor D, Yu-Poth S, Huth P, Moriarty K, Fishell V, et al. Polyunsaturated fatty acids in the food chain in the United States. American Journal of Clinical Nutrition 2000; 71(Suppl.): 179S-88S.

9 Yep YL, Li D, Mann NJ, Bode O, Sinclair AJ. Bread enriched with microencapsulated tuna oil increases plasma docosahexaenoic acid and total omega-3 oils in humans. Asia Pacific Journal of Clinical Nutrition 2002; 11: 285-91. 
10 Naylor NL, Goldberg RJ, Primavera JH, Kautsky N, Beveridge MCM, Clay J, et al. Effect of aquaculture on world fish supplies. Nature 2000; 405: 1017-24.

11 Myers RA, Worm B. Rapid worldwide depletion of predatory fish communities. Nature 2003; 423: 280-3.

12 Nichols PD. Sources of long-chain omega-3 oils. Lipid Technol 2004; 16: 247-51.

13 Robert SS, Singh SP, Zhou X-R, Petrie JR, Blackburn SI, Mansour PM, et al. Metabolic engineering of Arabidopsis to produce nutritionally important DHA in seed oil. Functional Plant Biology 2005; 32: 473-9.

14 Hansen J, Holm L, Frewer L, Robinson P, Sandoe P. Beyond the knowledge deficit: recent research into lay and expert attitudes to food risk. Appetite 2003; 41: 111-21.

15 O'Connor E, Cowan C, Williams G, O'Connell J, Boland MP. Irish consumer acceptance of a hypothetical secondgeneration GM yogurt product. Food Quality and Preference 2006; 17: 400-11.

16 Burton M, Pearse D. Consumer attitudes towards genetic modification, functional foods and micro-organisms: a choice modelling experiment for beer. AgBioForum 2002; 5: $51-8$.

17 Frewer LJ, Howard C, Shepherd R. The influence of realistic product exposure on attitudes towards genetic engineering of food. Food Quality and Preference 1996; 7: 61-7.

18 Lahteenmaki L, Grunert K, Ueland O, Astrom A, Arvola A, Bech-Larsen T. Acceptability of genetically modified cheese presented as a real product alternative. Food Quality and Preference 2002; 13: 523-33.

19 Frewer LJ, Howard C, Hedderley D, Shepherd R. Consumer attitudes towards different food-processing technologies used in cheese production - the influence of consumer benefit. Food Quality and Preference 1997; 8: 271-80.

20 Scholderer J, Frewer L. The biotechnology communication paradox: experimental evidence and the need for a new strategy. Journal of Consumer Policy 2003; 26: 125-57.

21 Grunert KG, Bech-Larsen T, Lahteenmaki L, Ueland O, Astrom A. Attitudes towards the use of GMO's in food production and their impact on buying intention: the role of positive sensory experience. Agribusiness 2004; 20: 95-107.

22 Wilson C, Evans G, Leppard P, Syrette J. Reactions to genetically modified food crops and how perception of risks and benefits influences consumers' information gathering. Risk Analysis 2004; 24: 1311-21.

23 Patch CS, Tapsell LC, Williams PG. Attitudes and intentions toward purchasing novel foods enriched with omega-3 fatty acids. Journal of Nutrition Education and Behavior 2005; 3: $1-7$.

24 Maddux J, Rogers R. Protection motivation theory and selfefficacy: a revised theory of fear appraisals and attitude change. Journal of Experimental Social Psychology 1983; 19: 469-79.

25 Cox DN, Koster A, Russell CG. Predicting intentions to consume functional foods and supplements to offset memory loss using an adaptation of Protection Motivation Theory. Appetite 2004; 43: 55-64.

26 Cox DN, Bastiaans K. Understanding Australian consumers' perceptions of selenium and motivations to consume selenium enriched foods. Food Quality and Preference 2007; 18: 66-76.

27 Green P, Srinivasan V. Conjoint analysis in consumer research: issues and outlook. Journal of Consumer Research 1978; 5: 103-23.

28 Green P, Srinivasan V. Conjoint analysis in marketing: new developments with implications for research and practice. Journal of Marketing 1990; (October): 3-19.

29 Australian Institute of Health and Welfare. Australia's Health [online], 2004. Available at http://www.aihw. gov.au/publications/index.cfm/title/10014. Accessed June 2005.
30 Australian Bureau of Statistics. Census of Population and Housing: 2001 Census Basic Community Profiles: Main Areas - by location name: South Australia: Basic Community Profile: B12 Highest level of schooling completed [data table online]. Available at http://www.abs. gov.au/websitedbs/D3110124.NSF/24e5997b9bf2ef35ca2567 fb00299c59/034b261536480e03ca256c3a0000d6a8!Open Document. Accessed June 2005.

31 Godin G, Shepherd RJ. A simple method to assess exercise behaviour in the community. Canadian Journal of Applied Sport Science 1985; 10: 141-6.

32 Pereira MA, Fitzgerald SJ, Gregg EW, Joswiak ML, Ryan WJ, Suminski RR, et al. A collection of physical activity questionnaires for health related research. Medicine and Science in Sports and Exercise 1997; 29(Suppl.): S36-8.

33 Baghurst KI, Record SJ. A computerised dietary analysis system for use with diet diaries or food frequency questionnaires. Community Health Studies 1984; 8: 11-18.

34 Cox DN, Evans G, Lease HJ. The influence of information and beliefs about technology on the acceptance of novel food technologies: a conjoint study of farmed prawns. Food Quality and Preference 2007; in press.

35 Cox DN, Evans G, Lease HJ. The acceptance of genetically modified oilseeds as sources of long chain omega-3 fatty acids: a conjoint study. Food Quality and Preference, submitted.

36 Patch CS, Tapsell LC, Mori TA, Meyer BJ, Murphy KJ, Mansour J, et al. The use of novel foods enriched with long chain $n-3$ fatty acids to increase dietary intake: a comparison of methodologies assessing nutrient intake. Journal of the American Dietetic Association 2005; 105: 1918-26.

37 Milne S, Sheeran P, Orbell S. Prediction and intervention in health related behaviour: a meta-analytic review of protection motivation theory. Journal of Applied Social Psychology 2000; 30: 143-66.

38 Armitage CJ, Conner M. Efficacy of the theory of planned behaviour: a meta analytic review. British Journal of Social Psychology 2001; 40: 471-99.

39 Schwarzer R, Fuchs R. Self efficacy and health behaviours. In: Conner M, Norman P, eds. Predicting Health Behaviour, 1st ed. Maidenhead: Open University Press/McGraw Hill Education, 1998; 163-96.

40 Rozin P, Spranca M, Krieger Z, Neuhaus R, Surillo D, Swerdlin A, et al. Preference for natural: instrumental and ideational/moral motivations, and the contrast between foods and medicines. Appetite 2004; 43: 147-54.

41 Rozin P. The meaning of natural. Psychological Science 2005; 16: 652-8.

42 Kennel WB, D'Agostino RB, Cobb JL. Effect of weight on cardiovascular disease. American Journal of Clinical Nutrition 1996; 63(Suppl.): 419S-22S.

43 Cox DN, Evans G, Lease H. The acceptance of genetically modified oilseeds as sources of long chain omega-3 fatty acids: a conjoint study. Abstract presented at 2006 Australasian Section Meeting of The American Oil Chemists' Society. Food Australia 2007; 59: 135-6.

44 Foran JA, Good DH, Carpenter DO, Hamilton MC, Knuth BA, Schwager SJ. Quantitative analysis of the benefits and risks of consuming farmed and wild salmon. Journal of Nutrition 2005; 135: 2639-43.

45 Hites RA, Foran JA, Carpenter DO, Hamilton MC, Knuth BA, Schwager SJ. Global assessment of organic contaminants in farmed salmon. Science 2004; 303: 226-9.

46 US Department of Health and Human Services and US Environmental Protection Agency. What You Need to Know About Mercury in Fish and Shellfish. 2004 EPA and FDA Advice For: Women Who Might Become Pregnant, Women Who are Pregnant, Nursing Mothers, Young Children [online], March 2004. Available at http://www.cfsan.fda. gov/ dms/admehg3.html. Accessed June 2005. 